\title{
Functional capacity and treatment data from a community based study of patients with rheumatoid arthritis
}

\author{
SUSAN G OWEN, ${ }^{1}$ WILLIAM T FRIESEN ${ }^{1}$ MICHAEL S ROBERTS, \\ HILTON FRANCIS, ${ }^{3}$ AND WILLIAM FLUX ${ }^{2}$
}

From the ${ }^{\prime}$ School of Pharmacy and the ${ }^{2}$ Department of Physiology, University of Tasmania; and the ${ }^{3}$ Royal Hobart Hospital, Tasmania, Australia

SUMMARY A community based study of rheumatoid arthritis was undertaken to determine patient characteristics and the patterns of treatment. Three hundred and eighty subjects were visited in their homes throughout Tasmania (pop. 430000 ) by a research team. The median age of the sample was 60 years (interquartile range (IR) 49-69), with a female predominance of $2 \cdot 65$ to 1 . The average onset age was 41 years (IR 30-53). Prescribing data indicated that polypharmacy was not common in the community, and that the use of slow acting antirheumatic drugs (SAARDs) and oral corticosteroids was not widespread. At the time of the study $26 \%$ of subjects were assayed fully functional-class I of the American Rheumatism Association's (ARA) functional classifications. The functional capacity data provided evidence that the spectrum of rheumatoid arthritis found in the community differed from that found in specialist rheumatology clinics.

Key words: non-steroidal anti-inflammatory drugs, population study, cross sectional study, disability, impact of rheumatoid arthritis, corticosteroids, slow acting antirheumatic drugs, prescribing patterns, drug therapy, gold/drug therapy.

Rheumatoid arthritis (RA) is a major chronic disease associated with many medical problems and is the cause of considerable limitation of physical achievement and social activities. Although some therapeutic measures appear to improve the clinical picture, the influence of drug therapy on the course of the disease remains in dispute. ${ }^{12}$

Several long term studies of hospital/clinic based patients have found that within 10 years $30-50 \%$ of the patients were 'severely disabled' (classes III and IV of the Steinbrocker classifications for functional capacity $\left.^{3}\right){ }^{2}$ Two separate studies showed that RA also caused significant social and economic disadvantage. ${ }^{2}+$ Most studies of rheumatoid arthritic populations have been carried out in hospital clinic environments and include prospective surveys of hospital admissions ${ }^{5}$ and retrospective ${ }^{6}$ and

Accepted for publication 25 September 1985.

Correspondence to Dr Susan G Owen. School of Pharmacy, University of Tasmania. PO Box 252C. Hobart. Tasmania 7001. Australia. prospective studies ${ }^{7}$ of outpatients. The majority of rheumatoid arthritis sufferers, however, are treated in the community by general practitioners. ${ }^{2}$ Furthermore, studies in busy outpatient clinics or hospitals may lead to an artificial assessment of function, ${ }^{89}$ hence assessment in the home is to be preferred. Few studies have examined patients with rheumatoid arthritis in their homes.

Tasmania (Fig. 1), the island state of Australia, has a relatively static population $(n=430000$ approx.) and manageable geographical characteristics (land mass equivalent to the Republic of Ireland), making it particularly suitable for research in the community. In addition, it has the advantage of an independent community based patient support organisation, the Rheumatism and Arthritis Foundation of Tasmania (RAFT).

The aims of this study were to record cross sectional data for a sample of patients with rheumatoid arthritis by considering onset, nature of care in the community, prescribing patterns, efficacy of treatment, and outcome with respect to disability 


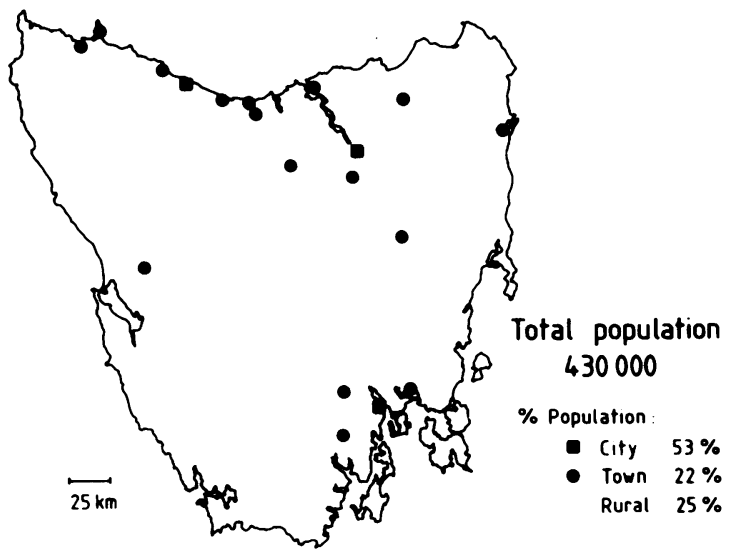

Fig. 1 The state of Tasmania.

and socioeconomic impact. This was to form a data base for a longitudinal study into the relationship between drug treatment and patient outcome as advocated by Fries. ${ }^{10}$

In this work we describe the major findings of the study, providing data on the sample characteristics, prescribing patterns, treatment retrospectively, disability, and social impact in a rheumatoid arthritis population based in one community.

\section{Patients and methods}

Subjects who had at sometime been diagnosed as having rheumatoid arthritis were recruited through the RAFT organisation (people visited by the RAFT officer and other RAFT members), medical practitioners, and media publicity. Subjects were visited in their homes by a research team which included a medical practitioner and an interviewer.
Subjects who had 'classical', 'definite', or 'probable' rheumatoid arthritis, according to the ARA criteria, ${ }^{11}$ at the time of interview were included. Any doubtful cases were confirmed by reference to 0 local medical practitioners and medical or hospital records.

The administered questionnaire (Appendix 1) was $\stackrel{\varnothing}{\varnothing}$ designed to elicit sociodemographic data, such as age of onset and therapeutic histories. The latter were obtained with verbal and visual prompting in? the form of a tablet board. Current medication was $\vec{\omega}$ also cited and recorded. Data associated witho outcome, such as earning capacity, was also col- $\frac{\omega}{0}$ lected. The extent of each subject's disability was. scored with the functional index of Lee et al, ${ }^{12}$ while the functional capacity of the subjects was classifiedis by the research medical practitioner according to the ARA functional classes. ${ }^{3}$

The accuracy of the data obtained in the study wasverified after the interview by cross checking with information recorded independently by a rheumatologist for a sample of 60 subjects. At least $25 \vec{\bullet}$ points were compared, involving details of onset of 0 arthritis, medication received, response to medication (efficacy, toxicity, etc), surgery undergone, additional medical problems, and characteristics of the arthritis.

Twenty millilitres of blood was taken by vene-气ूँ puncture during the home visit. Two millilitres of $\mathcal{Q}$ blood was collected in citrated tubes, stored at $4^{\circ} \mathrm{C}$, $\overline{0}$ and the erythrocyte sedimentation rate determined $\exists$ an average of four hours after collection by the Westergren method. The remainder of the sample was heparinised and immediately centrifuged. The plasma was stored at $-20^{\circ} \mathrm{C}$ for later analyses such? as rheumatoid factor titre.

The statistical data were analysed with a computer. with the statistical package for social sciences, ${ }^{13}$ in

Table 1 Sample characteristics

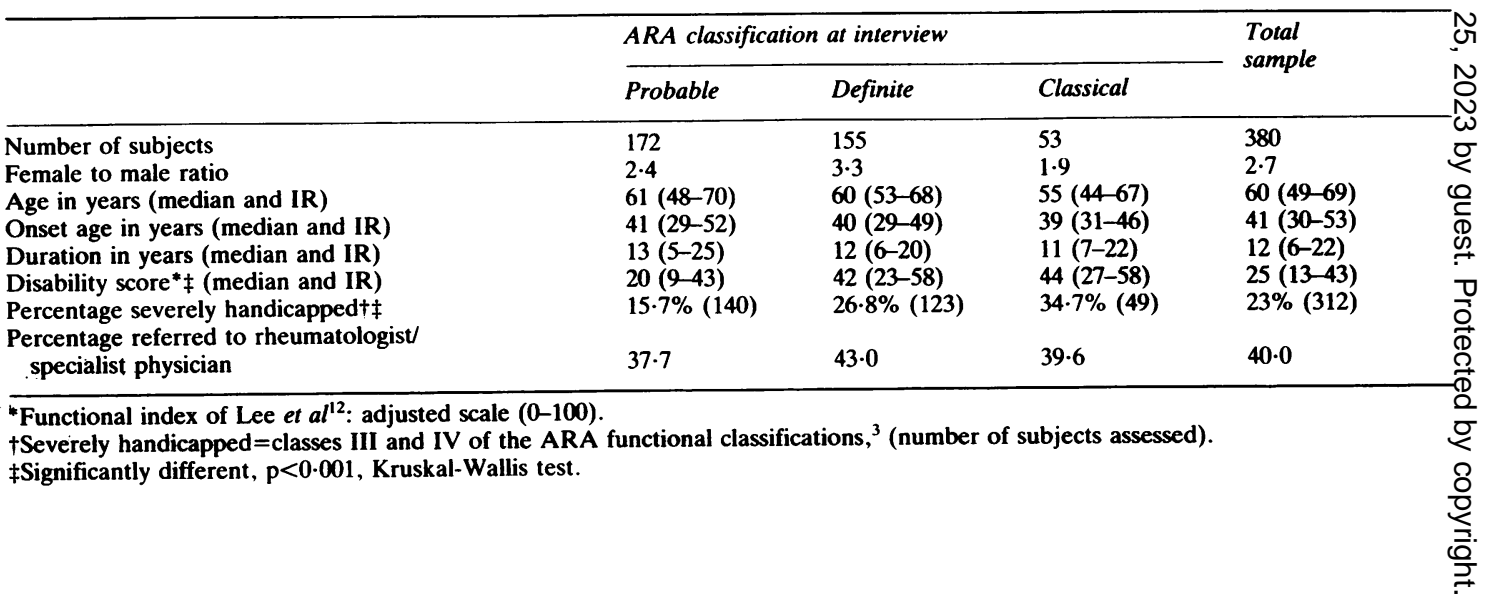


consultation with a statistician. Non-parametric statistics, including Mann-Whitney $U$ test and $\chi^{2}$ test, were used as not all variables were normally distributed (e.g., disease duration). All sample distributions were expressed as medians and interquartile ranges.

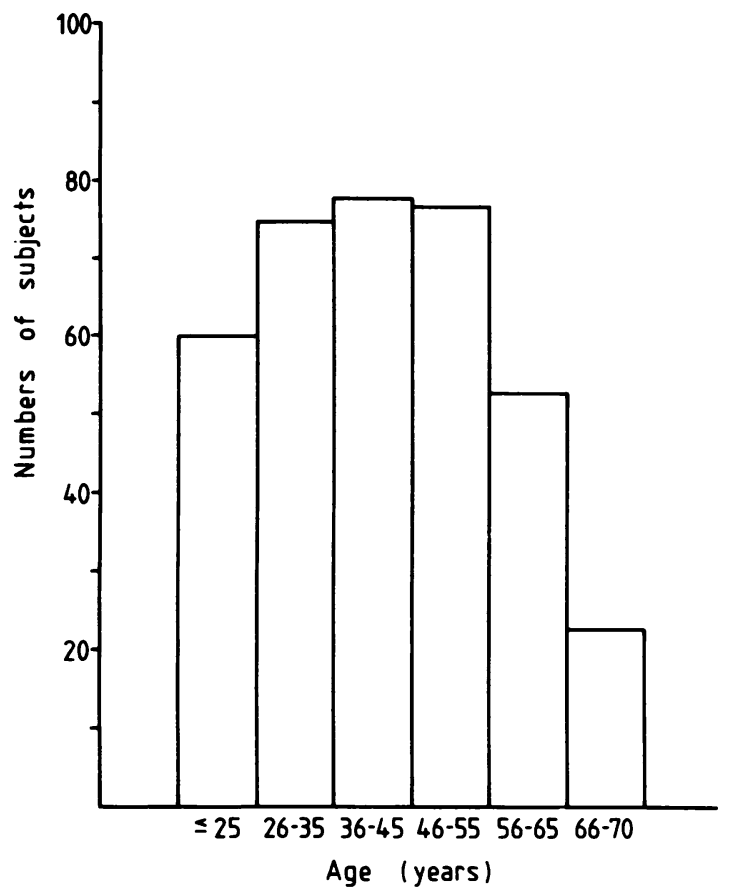

Fig. 2 Frequency distribution of onset ages.

\section{Results}

SAMPLE STATISTICS

Three hundred and eighty subjects, 276 women and 104 men, were included in the study, giving a female predominance of 2.65 to 1 . Fifty five per cent of the sample was classified as having classical or definite RA at the time of interview, and the remainder were classed as probable (Table 1). The median onset age was 41 years (IR 30-53), and a significant difference (Mann-Whitney $U$ test, $p<0.001$ ) existed in the distribution of onset ages of men, 48 years (IR 36-56), and women, 39 years (IR 27-52). Additional sample statistics are given in Table 1 and Fig. 2.

Neither the method of recruitment nor the location of the subject alone affected the sample statistics with respect to average age, duration, and disability. The combination of location (i.e., city, large town, or rural areas) and method of recruitment was significant, with subjects recruited through the support organisation in the cities tending to have a greater level of disability compared with the remainder of the sample (Table 2). There was a degree of overlap in the source of subjects, especially in rural areas. The majority of rural subjects were included as RAFT sources, but $60 \%$ of these had been referred to RAFT by the local medical practitioners. There was only a $6 \%$ overlap among the other sources.

Of the 60 sets of data compared with the rheumatologist's medical history, only one set failed to be at least $96 \%$ accurate, with two differences occurring, one related to previous use of predniso-

Table 2 Characteristics of samples from various sources

\begin{tabular}{|c|c|c|c|}
\hline & & $R A F T(n=255)$ & $\begin{array}{l}\text { Other sources } \\
(n=125)\end{array}$ \\
\hline City $(n=152)$ & $\begin{array}{l}\text { Number of subjects } \\
\text { Age in ycars (median and IR) } \\
\text { Duration in years (median and IR) } \\
\text { Disability score } \dagger \text { (median and IR) } \\
\text { Percentage severely handicapped } \ddagger\end{array}$ & $\begin{array}{l}90 \\
59(51-67) \\
14(8-28) \\
38(23-57) 8 \\
36 \cdot 4 \%(88)\end{array}$ & $\begin{array}{l}62 \\
58(42-67) \\
12(2-22) \\
23(13-42) \\
17 \cdot 5 \%(57)\end{array}$ \\
\hline Large towns $(n=121)$ & $\begin{array}{l}\text { Number of subjects } \\
\text { Age in years (median and IR) } \\
\text { Duration in years (median and IR) } \\
\text { Disability score } \dagger \text { (median and IR) } \\
\text { Percentage severely handicapped } \frac{\dagger}{\div}\end{array}$ & $\begin{array}{l}81 \\
61(50-68) \\
13(6-23) \\
25(8-39) \\
15 \cdot 7 \%(51)\end{array}$ & $\begin{array}{l}40 \\
60(43-71) \\
11(3-23) \\
18(4-38) \\
17 \cdot 7 \%(34)\end{array}$ \\
\hline Rural arcas $(n=107)$ & $\begin{array}{l}\text { Number of subjects } \\
\text { Age in years (median and IR) } \\
\text { Duration in ycars (median and IR) } \\
\text { Disability score } \dagger \text { (median and IR) } \\
\text { Percentage severely handicapped } \frac{\hbar}{\dagger}\end{array}$ & $\begin{array}{l}84 \\
60(53-70) \\
10(6-18) \\
24(12-40) \\
18 \cdot 5 \%(65)\end{array}$ & $\begin{array}{l}23 \\
58(50-70) \\
11(5-17) \\
20(4-55) \\
23 \cdot 5 \%(17)\end{array}$ \\
\hline
\end{tabular}

*Other sources included doctors' referrals and media publicity volunteers.

†Functional index of Lee et al. ${ }^{12}$ : adjusted scale $0-100$.

¥Severely handicapped=classes III and IV of the ARA functional classifications, ${ }^{3}$ (number of subjects assessed).

§Significantly different from total sample disability, $25(13-43)$; $p<0 \cdot 001$, Mann-Whitney U test. 
lone and the other to type of surgery. Nine of the 60 had only one discrepancy. In the majority of cases this single point was the presence of Sjögren's syndrome. At interview eight subjects made no report of any eye or other problem associated with the syndrome but were later deemed to have a mild Sjögren's syndrome by the rheumatologist. The other discrepancy was previous hydroxychloroquine treatment. The data sets were otherwise consistent. Thus the information obtained during the interview was considered to have acceptable reliability.

\section{CARE AND TREATMENT}

Forty per cent of the subjects had at sometime consulted a specialist physician or rheumatologist, and $16 \%$ were currently being treated by a rheumatologist, specialist, or attending a hospital outpatients' clinic. Forty eight per cent of subjects had previously been hospitalised for reasons directly related to their arthritis, a fifth of these on more than four occasions. Twenty seven per cent of the total sample had undergone corrective surgery.

Two thirds of the subjects had at sometime had

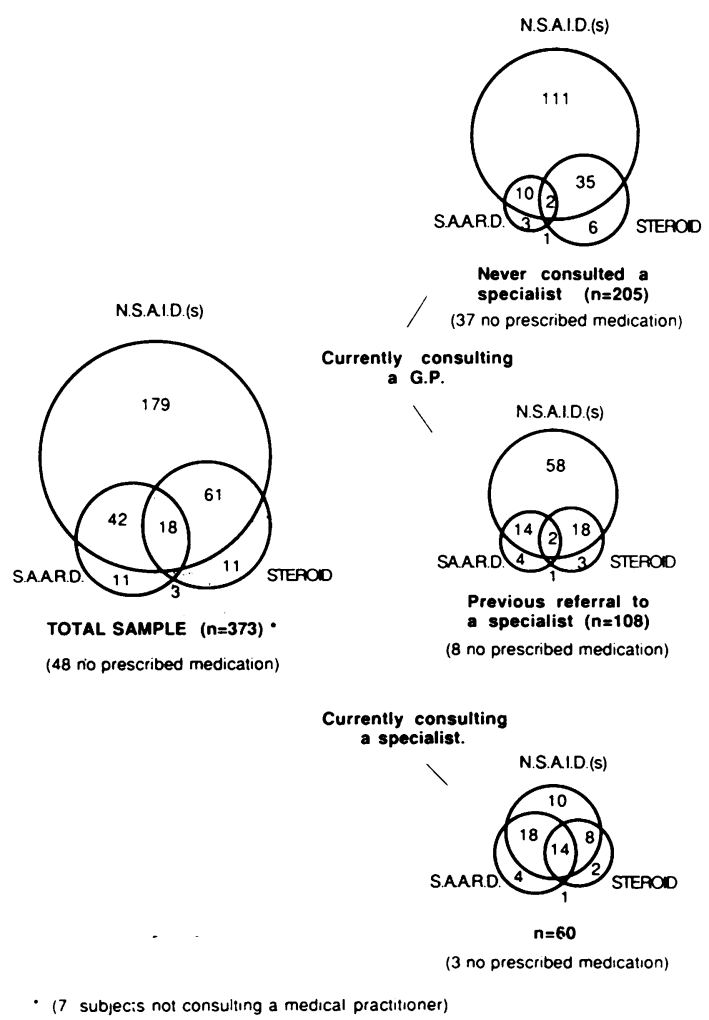

Fig. 3 Current prescribing patterns. physiotherapy. Referral to physiotherapy was more 을. common $(77 \%)$ among the 152 subjects who had attended a clinic, rheumatologist, or a specialist $\stackrel{\mathcal{F}}{\stackrel{P}{+}}$ physician, compared with $59 \%$ of the 228 subjects who had received only primary care $\left(\chi^{2}\right.$ test, $\mathrm{p}<0.001)$.

Fig. 3 summarises the current prescribing patterns $\stackrel{\square}{\circledR}$ in the sample. Fifteen per cent of the subjects had no prescribed medication, while $44 \%$ had only one $\vec{\circ}$ medication. In most cases this was a non-steroidal anti-inflammatory drug (NSAID). Six per cent were treated with a second line drug or corticosteroid $O$ alone. Twenty per cent of the sample were currently $\frac{0}{2}$ receiving a slow acting antirheumatic drug (SAARD): 38 parenteral gold, 17 D-penicillamine, 12 cytotoxic drugs, and 13 antimalarial drugs. Six i subjects were on two SAARDs. Twenty five per $\stackrel{\omega}{\omega}$ cent were taking oral corticosteroids. In the ma- 의 jority $(85 \%)$ of cases this was chronic maintenance therapy of more than two years' duration. The $\frac{7}{0}$ prescribing of SAARDs and corticosteroids was significantly associated with referral to a rheuma- $\vec{\bullet}$ tologist or specialist physician $\left(\chi^{2}\right.$ test, $\left.p<0 \cdot 01\right)$. \&

A retrospective audit of discontinued therapy showed that 161 subjects $(42 \%)$ had previously had chrysotherapy. A much smaller proportion had taken other SAARDs (D-penicillamine 9\%, antimalarial drugs $11 \%$, cytotoxic drugs $1 \%$ ) or corti- $\frac{\circ}{\varnothing}$ costeroids $13 \%$, or both. With discontinued therapy also there was a significant association between 0 utilisation of second line drugs and referral to a rheumatologist/specialist physician $\left(\chi^{2}\right.$ test, $\mathrm{p}<$ $0 \cdot 001$ ). Sixty per cent of these subjects had a history of treatment with a SAARD and $20 \%$ with a corticosteroid, compared with $34 \%$ and $10 \%$ respectively of the 228 subjects who had never been referred. All subjects had been prescribed NSAIDs during the course of their disease.

Among the $42 \%$ who had received gold $57 \%$ hado ceased treatment due to an adverse drug reaction? $(A D R)$ and $21 \%$ due to ineffectiveness $(n=24)$ oro loss of benefit $(n=10)$. Of the remaining 35 subjects, 11 had only one six month course of gold, four had or stopped therapy for other reasons, and the rest had $N$ ceased after improvement in their condition. The N spectrum of ADRs which prevented continued therapy is listed in Table 3. The majority of the adverse effects were experienced in the first six months of treatment, but 12 subjects had two or $\stackrel{\oplus}{\rightarrow}$ more years of successful treatment before compli- 0 cations caused parenteral gold to be stopped.

D ISABILITY AND IMPACT
The functional capacities of the subjects were $\frac{\mathbb{Q}}{\sigma}$ assessed both by the Steinbrocker classification and by Lee's functional index score (scale adjusted to응 
Table 3 Patient reported toxicity to gold

\begin{tabular}{lr}
\hline Total number of subjects & 161 \\
Mucocutaneous reactions & 44 \\
Haematuria, proteinuria & 16 \\
Haematological & 6 \\
Malaise/weight loss & 13 \\
Exacerbation of arthritis & 4 \\
Other miscellaneous & 9 \\
Number of subjects reporting toxicity & 92 \\
Percentage of total & 57 \\
\hline
\end{tabular}

$0-100)$. There was a significant association $(\mathrm{p}<0.001$ Kruskal-Wallis test) between the two measures (Table 4). Three hundred and twelve subjects were ARA classified. The median Lee disability scores for those who had not been ARA classified was 29 (IR 20-45). This was not significantly different from the score for those who had been classified-25 (IR 13-43) (Mann-Whitney U test). Of the subjects assessed by the Steinbrocker classification, $26 \%$ were classed 'fully functional' (ARA class I). The majority of the sample $(51 \%)$ were able to conduct 'normal activities despite discomfort or joint limitation' (ARA class II), and $20 \%$ were 'significantly limited in their usual activities' (ARA class III). The remaining $3 \%$ were classed as 'largely or wholly incapacitated' (ARA class IV). The significant effect of disease duration on functional capacity $\left(\chi^{2}\right.$ test, $\mathrm{p}<0.001$ ) is shown in Table 5.

Irrespective of duration of disease and proportion of subjects who were 'severely handicapped' (classes III and IV of the ARA functional classification) tended to be greater among those who had at sometime been referred to a specialist (Table 6). Even though the two care categories had similar disease durations, the age distributions were significantly different (Mann-Whitney, $\mathrm{p}<0.01$ ). Those who had been referred to a rheumatologist or specialist physician tended to be younger (57 years, IR 47-66) than those who had received only primary care (62 years, IR 51-70).

The 60 subjects who were currently consulting a specialist also tended to be younger (53 years, IR

Table 4 Relation* between ARA functional grades and Lee's functional index score ${ }^{2}$

\begin{tabular}{lllll}
\hline ARA class & I & II & III & IV \\
Disability score $+($ median and IR) & $8(3-13)$ & $25(18-38)$ & $49(39-67)$ & $83(74-99)$ \\
\hline
\end{tabular}

${ }^{*}$ Significant association, $\mathrm{p}<0.001 \mathrm{Kruskal}-$ Wallis test.

†Scale adjusted to $0-100$.

Table 5 Relation between ARA functional grades and disease duration

\begin{tabular}{|c|c|c|c|c|c|}
\hline \multirow{2}{*}{$\begin{array}{l}\text { Duration } \\
\text { range (years) }\end{array}$} & \multirow{2}{*}{$\begin{array}{l}\text { No of } \\
\text { subjects }\end{array}$} & \multicolumn{4}{|c|}{ Percentage of subjects in each $A R A$ class } \\
\hline & & $I$ & $I I$ & $I I I$ & IV \\
\hline $\begin{array}{c}0-2 \\
3-5 \\
6-10 \\
11-20 \\
>20\end{array}$ & $\begin{array}{l}39 \\
38 \\
71 \\
82 \\
82\end{array}$ & $\begin{array}{l}41 \cdot 0 \\
31 \cdot 6 \\
29 \cdot 6 \\
24 \cdot 4 \\
14 \cdot 6\end{array}$ & $\begin{array}{l}59.0 \\
55.2 \\
53.5 \\
50.0 \\
43.9\end{array}$ & $\begin{array}{r}0 \cdot 0 \\
13 \cdot 2 \\
14 \cdot 1 \\
23 \cdot 2 \\
35 \cdot 4\end{array}$ & $\begin{array}{l}0 \cdot 0 \\
0 \cdot 0 \\
2 \cdot 8 \\
2 \cdot 4 \\
6 \cdot 1\end{array}$ \\
\hline
\end{tabular}

Table 6 Degree of handicap compared for subjects stratified by disease duration and medical care

\begin{tabular}{|c|c|c|c|c|}
\hline \multirow[t]{2}{*}{$\begin{array}{l}\text { Duration } \\
\text { range (years) }\end{array}$} & \multicolumn{2}{|c|}{$\begin{array}{l}\text { Subjects treated only by general practitioner } \\
\text { (median duration } 11 \text { years) }\end{array}$} & \multicolumn{2}{|c|}{$\begin{array}{l}\text { Subjects referred to a specialist } \\
\text { (median duration } 12 \text { years)* }^{*}\end{array}$} \\
\hline & No of subjects & $\begin{array}{l}\text { Percentage severely } \\
\text { handicapped }\end{array}$ & No of subjects & $\begin{array}{l}\text { Percentage severely } \\
\text { handicapped }\end{array}$ \\
\hline $\begin{array}{c}0-2 \\
3-5 \\
6-10 \\
11-20 \\
>20\end{array}$ & $\begin{array}{l}29 \\
17 \\
43 \\
48 \\
43\end{array}$ & $\begin{array}{l}0 \\
5 \cdot 0 \\
14 \cdot 0 \\
20 \cdot 8 \\
23 \cdot 3\end{array}$ & $\begin{array}{l}10 \\
21 \\
28 \\
34 \\
39\end{array}$ & $\begin{array}{c}0 \\
19 \cdot 1 \\
21 \cdot 4 \\
26 \cdot 5 \\
61 \cdot 6\end{array}$ \\
\hline Total & 180 & $15 \cdot 0$ & 132 & $32 \cdot 6$ \\
\hline
\end{tabular}

*No statistical difference in disease duration (Mann-Whitney $U$ test).

+Severely handicapped=classes III and IV of ARA functional classification. 


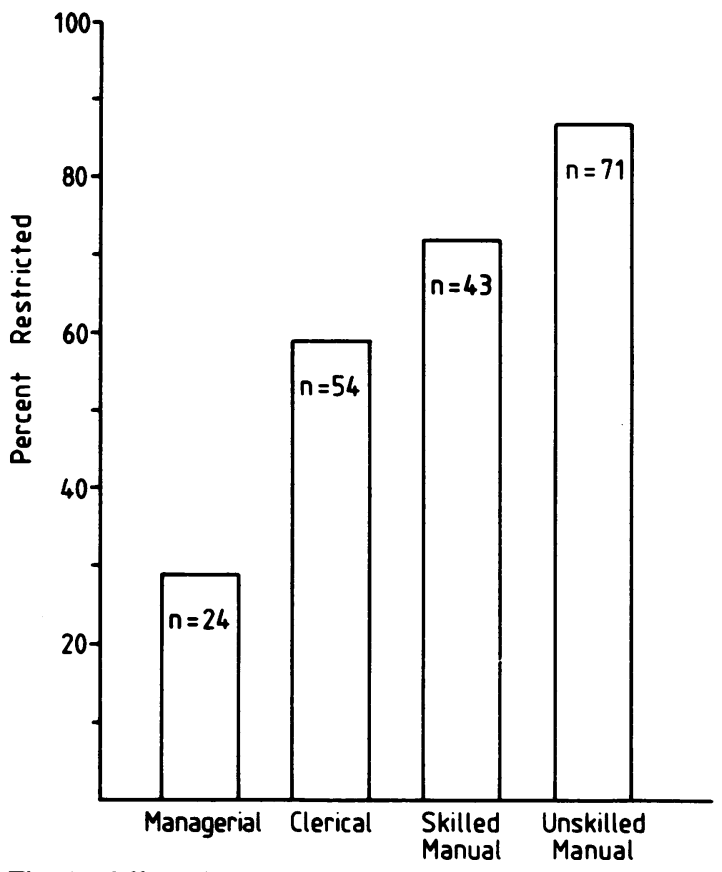

Fig. 4 Effect of workplace autonomy on earning capacity.

43-64) than those currently treated in community practice (61 years, IR 51-70) (Mann-Whitney U test, $\mathrm{p}<0.001)$. There was also a similar trend towards more severe disease in the group under current specialist care, but this did not reach statistical significance. Thirty one per cent of the 60 in this group were 'severely handicapped' compared with $22 \%$ among those receiving primary care. The distributions of disease duration were also not significantly different in the two current care categories.

The dramatic impact of rheumatoid arthritis was reflected by its effect on the subjects' earning capacity. Sixty six per cent of 192 subjects, who were employed at the time of disease onset, had had their earning capacity restricted by arthritis (through early retirement, change of work type, extended periods of absence, or a complete inability to continue working). Men tended to be more affected, $\frac{0}{\infty}$ $78 \%$ having their earning ability restricted, compared with $60 \%$ of women. Type of employment $\stackrel{=}{?}$ had a significant influence on a person's earningo capacity $\left(\chi^{2}\right.$ test, $\left.p<0 \cdot 001\right)$. The earning ability of 을 persons with a high degree of autonomy at work, $\frac{\overline{5}}{\frac{1}{2}}$ i.e., managerial positions or self employed, was less $\stackrel{\mathbb{Q}}{\Omega}$ restricted than that of more dependent workers (Fig. 4).

Two hundred and two subjects were of working. age (men $15-65$ years, women $15-60$ years). Five $\vec{\omega}$ men and one woman were not working for reasons ${ }^{\circ}$ other than arthritis, and of the women, 45 expressed no desire to be in the workforce, being engaged full time in home duties. Of the 151 remaining subjects, of only $37 \%$ were in full time employment, $23 \%$ were receiving an invalid pension, $16 \%$ had retired early $\omega_{\omega}$ or were receiving another pension or benefit (de- $\mathrm{O}$ serted wife pension, unemployment, etc), and $24 \%$ were supported by his/her spouse (Table 7).

\section{Discussion}

Our sample statistics were consistent with previous population study data of rheumatoid arthritis with respect to age of onset and sex ratio. ${ }^{14} 15$ The proportion with 'probable' rheumatoid arthritis is associated with the remittent nature of the disease. ${ }^{16} \stackrel{\circ}{\otimes}$ The majority of those classed as 'probable' had a $\stackrel{2}{\Rightarrow}$ clearly defined history of RA, and all subjects had been diagnosed as having the disease at some time. The characteristics of subjects in the various ARA classes were similar, with the exception of the degree of disability, which was greater in those with $\frac{ \pm}{2}$ 'classical' and 'definite' disease. Since the number of $\dot{ }$ ARA criteria present is related to disease severity, ${ }^{17}$ a larger proportion of subjects with 'probable' disease would be expected in a community study.

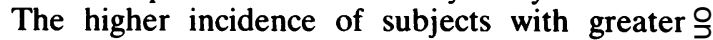
disability among those reached through RAFT in $>$ the cities may be a consequence of the different nature of the patient support organisations in the $N$ various locations. The organisation appears to be serving different needs in rural areas, where it assists $\mathcal{N}$ the general practitioners with patient education and $\tilde{W}^{N}$

Table 7 Effect of rheumatoid arthritis on current working status

\begin{tabular}{|c|c|c|c|}
\hline & Male & Female & Total \\
\hline \multicolumn{4}{|l|}{ orking } \\
\hline age wishing to work & 53 & 98 & 151 \\
\hline Percentage receiving invalid pension & 39 & 14 & 23 \\
\hline Percentage receiving other pension & 19 & 14 & 16 \\
\hline Percentage supported by spouse & 6 & 34 & 24 \\
\hline Percentage fully employed & 36 & 38 & 37 \\
\hline
\end{tabular}


support. In the urban areas, which have other support mechanisms and more public facilities, RAFT appears to be involved in dealing with the social isolation of patients with arthritis.

The observation that $60 \%$ of our sample had never been referred to a specialist physician or rheumatologist is consistent with the premise that the majority of patients with rheumatoid arthritis are treated in community practice. ${ }^{29}$

There was a significant difference in current prescribing patterns between subjects who were receiving primary care and those who were being treated by a specialist. There were similar differences in the retrospective treatment data. In both current and retrospective data the use of SAARDs and corticosteroids was more common among those who had been referred to a specialist. In total, $52 \%$ of our 380 community based subjects had received chrysotherapy and $38 \%$ were prescribed oral corticosteroids at some time. By comparison, Meenan et $a l$, in a telephone survey of 245 patients sampled from rheumatology clinics and practices, found that $63 \%$ had received parenteral gold and the same proportion oral corticosteroids. ${ }^{4}$ These differences in prescribing patterns may be partly attributed to the nature of our community based sample. Patients with rheumatoid arthritis treated in specialist practice tend to be from the more severe end of the disease spectrum and thus receive more second line treatment. $^{2}$

Our retrospective information about the continued use of parenteral gold was similar to that reported from more controlled clinical situations. Rothermich et al in a prospective clinical trial of gold found that $79 \%$ of 95 subjects withdrew over a period of five years due to loss of benefit or unacceptable side effects. ${ }^{18}$ A similar proportion of our sample $(78 \%)$ ceased therapy for these reasons.

The spectrum and incidence of toxic reactions to chrysotherapy were also similar to those reported in clinical trials, ${ }^{17}$ mucocutaneous reactions being most common. The actual severity of these reactions is unknown as they were reported by the subjects, not the medical practitioners, but they were sufficient to cause therapy to be stopped.

The functional capacity data for our sample tended to support the concept that patients treated in community practice are from the more moderate end of the disease spectrum. This was further illustrated when our community based data was compared with a clinic study. Cosh and Rasker reported that $45 \%$ of their 54 surviving clinic patients were 'severely handicapped' (ARA classes III and IV) towards the end of the second decade of their disease. ${ }^{7}$ In our study only $26 \%$ of the 55 subjects with a similar disease duration (15-25 years) had developed this level of disability. Furthermore, it was only among those subjects $(n=61)$ who had had RA for more than 25 years (median 36 years) that the proportion who were 'severely handicapped' $(42 \%)$ was similar to the proportion in the clinic situation of Cosh and Rasker.

The impact of RA over the years in terms of altered lifestyle among the people in our sample was similar to that observed in studies by Scott et $\mathrm{al}^{2}$ and Meenan et $a l,{ }^{4}$ both conducted among patients consulting rheumatologists. In their studies and ours approximately two thirds of the subjects had suffered significant social disadvantage through diminution or loss of earning capacity.

Since rheumatoid arthritis is not a reportable condition it is difficult to obtain a randomly selected sample in a community study. We attempted to eliminate bias by obtaining the sample from as wide a base as possible throughout the state of Tasmania. Inclusions into our sample were stopped at 380 since successive additions of subjects did not change the characteristics of the sample but merely increased the significance levels when either parametric or non-parametric tests were applied. The actual number of patients with rheumatoid arthritis in the state is not known. Some guidance, however, as to the prevalence of RA is found in the Australian Bureau of Statistics (ABS) figures. ${ }^{20}$ The Australian health survey (1977-8) of chronic conditions estimated the prevalence of RA in Australia as $0.32 \%$ of the population over 15 years of age. This may be an underestimate as the prevalence of RA in most Caucasian adult populations is estimated as $1 \% .{ }^{21}$ If the ABS figure is applied the number of adult persons with rheumatoid arthritis in Tasmania would be approximately 1000 , and this report contains data on $38 \%$ of that estimated population.

The authors wish to thank the Tasmanian branch of the Arthritis Foundation of Australia, in particular the field officers, for their enthusiastic help. We also thank Mr D Scheimer. Dr D Evans, and $\mathrm{Mr}$ A Miller for their technical assistance and Mr G McPherson for his statistical consultation. We acknowledge the aid and ready encouragement given to us by Professor $\mathrm{N}$ Lickiss. Professor $\mathrm{P}$ Brooks. Dr A Maclaine-Cross. Dr L Hall, Dr K Muirden, Dr G Giles. Dr C Shugg, and the general practitioners in Tasmania. This work was supported by grants from the Menzies Foundation and the Arthritis Foundation of Australia.

\section{References}

1 Wright V. Amos R. Do drugs change the course of rheumatoid arthritis? Br Med J 1980; 280: 964-6.

2 Scott D L. Coulton B L. Chapman J H. Bacon P A. Popert A J. The long-term effects of treating rheumatoid arthritis. $J R$ Coll Physicians Lond 1983; 17: 79-85.

3 Steinbrocker O. Traeger C H. Batterman R C. Therapeutic criteria in rheumatoid arthritis. JAMA 1949; 140: 659-62.

4 Meenan R F. Yelin E H. Nevitt M. Epstein W V. The impact of chronic disease: a sociomedical profile of rheumatoid arthritis. Arthritis Rheum 1981: 24: 544-9. 
5 Duthie J J R, Brown P E, Truelove L H, Baragar F D, Lawrie A J. Course and prognosis in rheumatoid arthritis: a further report. Ann Rheum Dis 1964: 23: 193-202.

6 Ragan C, Farrington E. The clinical features of rheumatoid arthritis: prognostic indices. JAMA 1962: 181: 663-7.

7 Cosh J A, Rasker J J. A 20-year follow up of 100 patients with rheumatoid arthritis. Ann Rheum Dis 1982; 41: 317.

8 Mowat A G, Nichols P J R, Hollings E M. Haworth R J, Aitken L C. A comparison of follow-up regimes in rheumatoid arthritis. Ann Rheum Dis 1980; 39: 12-7.

9 Nichols P J R. Management of rheumatoid arthritis in the community. Int Rehabil Med 1979; 1: 200-3.

10 Fries J F. Toward an understanding of patient outcome measurement. Arthritis Rheum 1983; 26: 697-704.

11 Ropes M W. Diagnostic criteria for rheumatoid arthritis: 1958 revision by a committee of the American Rheumatism Association. Ann Rheum Dis 1959; 18: 49-53.

12 Lee P, Jasani M K. Dick W C, Buchanan W W. Evaluation of a functional index in rheumatoid arthritis. Scand $J$ Rheumatol 1973; 2 : 71-7.

13 Nie N H, Hull C H, Jenkins J G. Steinbrenner K. Bent D H. Statistical package for the social sciences. 2nd ed. New York: McGraw-Hill, 1970.

14 Hochberg M C. Adult and juvenile rheumatoid arthritis: current epidemiologic concepts. Epidemiol Rev 1981; 3: 27-44.

15 Luukkainen R, Isomaki H. Kajander A. Prognostic value of the type of onset of rheumatoid arthritis. Ann Rheum Dis 1983; 42: 274-5.

16 O'Sullivan J B, Cathcart E S. The prevalence of rheumatoid arthritis: follow-up evaluation of the effect of criteria on rates in Sudbury. Massachusetts. Ann Intern Med 1972: 76: 573-7.

17 Mitchell D M. Fries J F. An analysis of the American Rheumatism Association criteria for rheumatoid arthritis. Arthritis Rheum 1982; 25: 481-7.

18 Rothermich N O, Philips V K. Bergen W. Thomas M H. Follow up study of chrysotherapy. Arthritis Rheum 1979; 22: 423.

19 Gottlieb N L, Bjelle A. Gold compounds in rheumatoid arthritis: report of a symposium. Scand J Rheumatol 1977; 6: 225-30.

20 Australian Health Survey 1977-1978. Chronic conditions (illnesses and permanent disabilities). Canberra: Australian Bureau of Statistics, 1980.

21 Hochberg M C. Epidemiology of rheumatoid arthritis in developed countries. J Rheumatol 1983: suppl 10: 7-9.

\section{Appendix 1}

SUBJECTS were asked all questions. Details in brackets were probes or reminders for the interviewer

WEIGHT HEIGHT

NAME SEX-

\section{ADDRESS}

\section{QUESTIONNAIRE}

\section{Part 1. History}

1. Date of birth

3. Maiden name

2. Birthplace

4. Mother's maiden name

5. At what age was rheumatoid arthritis first diagnosed? (Prior details)

6. Was the onset of rheumatoid arthritis associated with a traumatic event in your life? (1/none, $2 /$ minor illness, 3 /major illness, 4/post-natal, 5/hysterectomy, 6/menopause, 7/accident-injury, $8 /$ major life event. $9 /$ stress).
7. Who made the initial diagnosis of rheumatoid arthritis?

8. Have you ever been referred to a specialist/rheumatologist? - $\overrightarrow{\overline{\vec{G}}}$ (names)

9. What joints were initially affected?/affected second?/how long after the 1st joint/s?

10. How would you classify your initial condition ( $1 / \mathrm{mild}$, $2 /$ moderately severe, 3 /severe)?

11. a. Have you ever been hospitalised for RA? (when/where/why?)

b. Have you had any surgery related to your RA? (details)

12. Do you have any relations (blood) who have/or have had rheumatoid arthritis?

(name and address)

3. Do you have any medical problems apart from RA? a. Heart/arterial disease (1/none, 2/CVA, 3/CHF, 4/angina, $5 /$ valve defect, 6/rheumatic heart, 7/RA defect, 8/other)?

b. Respiratory problem (1/none, 2/asthma, 3/COAD. 4/rheumatic lung prev.. 5/rheumatic lung now, 6/other)?

c. Diabetes (1/none. $2 /$ insulin depend. $3 /$ drug controlled. 4/diet controlled)?

d. Thyroid trouble (1/none, 2 previous hyperthyroid, 3/previous hypothyroid, 4/previous goitre, 5/hyperthyroid. 6/hypothyroid. 7/goitre. 8/other)?

e. Hormonal (1/none. 2 /hysterectomy, 3/pregnant, 4/other)?

f. Stomach trouble (1/none, $2 /$ duodenal ulcer, 3/gastric ulcer 4/ulcer, 5/hiatus hernia, 6/dyspepsia, 7/colitis. 8/constipation, 9/other)?

g. Kidney-bladder trouble (1/none, $2 /$ cystitis, $3 /$ nephritis, $4 /$ renal colic, $5 /$ drug reaction, $6 /$ dermatitis, 7/other)?

h. Skin problems (1/none, 2/psoriasis, 3/eczema, $4 /$ drug reaction, $5 /$ dermatitis, $6 /$ other)?

i. Eye trouble (1/none, 2/Sjögren's, 3/dry eyes, 4/drug reaction, $5 /$ cataracts, $6 /$ other)?

j. Any serious illness previously ( $1 /$ none, $2 /$ rheumatic fever, 3/glandular fever, 4/polio, 5/hepatitis, 6/hydatids, 7/cancer, $8 /$ other)? 
k. Any other medical condition (migraine, allergy, blood disorders, neurological problems)?

1. Have you had any surgery (gall bladder etc.)?

14. Have you ever had/tried any (a) physiotherapy, (b) alternative treatments for your rheumatoid? Please indicate effectiveness.

$\begin{array}{ll}1=\text { very effective } & 4=\text { condition worse } \\ 2=\text { some relief } & 5=\text { don't know } \\ 3=\text { not effective } & 6=\text { not tried }\end{array}$

a. physiotherapy

b. acupuncture

c. herbal remedies

d. copper bracelet

e. Seatone/Aquatone

f. others

(details of other and current)

15. Do you have or have you ever had any rheumatoid nodules (elbows, hands, base of spine)

16. a. Do you ever suffer any morning stiffness? (YES/NO)

b. How long did the morning stiffness last today (on average)?

17. How would you rule your current rheumatoid arthritis now: ( $1 /$ mild, $2 /$ moderately severe. $3 /$ severe)?

18. a. Are you in pain at present from the arthritis? YES/NO

b. If yes please indicate level

NO

PAIN

PAIN

AT ITS

WORST

19. a. How would you describe your current pain:

(1/continuous. 2/transient. 3/brief)

b. Do you need additional medication (other than prescribed) to relieve your pain? (YES/NO)

c. Do you find your pain is worse at certain times of day? (YES/NO)

20. Do you find that other things affect your arthritis (1/heat, 2/cold, 3/illness, 4/stress. 5/increased activity, 6/food)?

21. DISABILITY SCALE: Please indicate which best describes your ability to perform the following activities.

$1=$ Yes with no difficulty
$2=$ Yes but with difficulty (c.g. pain, weakness or stiffness) $3=$ No.

a. Can you turn your head from side to side?

b. Can you comb your hair (at the back)?

c. Can you close drawers (with arms only)?

d. Can you open doors?

e. Can you lift a full teapot?

f. Can you lift a cup with one hand to drink?

g. Can you turn a key in a lock?

h. Can you cut meat with a knife?

i. Can you butter bread?

j. Can you wind a watch?

k. Can you walk without

(i) someone's help?

(ii) walking frame?

(iii) crutches?

(iv) stick?

1. Can you walk up a flight of stairs?

m. Can you walk down a flight of stairs?

n. Can you stand up with your knees straight?

o. Can you stand on your toes?

p. Can you bend down to pick something up off the floor?

q. Can you take without assistance?
(i) a bath?
(ii) a shower?

22. Impact of arthritis:

a. Are you able to carry out normal tasks about the house/ garden without \{difficulty (1), appliances/aids (2), or assistance (3) \}?

b. Has your arthritis interfered with, or limited your schooling. work or houschold duties? \{No (1). Interfered (2). Prevented (3)\}

c. Has your arthritis restricted now or in the past your leisure activities, such as sport, hobbies, holidays etc.? \{No (1), Interfered (2). Prevented (3)\}

d. Does your arthritis limit or prevent social activities such as attending theatres, functions or parties? \{No (1). Interfered (2), Prevented (3) \}

e. Has your arthritis affected your earning capacity or income? $\{$ No (1), Yes (2)\}

f. Has your arthritis in any way affected your relationship with other people, \{(i.e., friends, family, spouse)? \{No (1). Yes (2)\} 
23. a. What prescribed medication are you currently having?

Aspirin (Bufferin, Ecotrin, Rhusal, SRA)

Ibuprofen (Brufen)

Indomethacin (Indocid)

Naproxen (Naprosyn)

Phenylbutazone (BTZ. Butazolidin)

Sulindac (Clinora)

Steroids (dexamethasone, prednisolone)

Cytotoxies, gold, D-penicillamine.

chloroquine

Others (Dolobid, Digesic, diflunisal, Benoral, Palaprin,

Panadinc, dilcofenac, ctc.)

(Exact details: brand, dose, duration)

b. Do you take anything else for pain?

c. What is YOUR reason for taking this medication (pain, stiffness, doctor, wife, arthritis)?

24. DO YOU EVER DELIBERATELY ALTER THE DOSE OF THIS MEDICATION?
a. increase or decrease according to level of pain
b. increase at night to reduce morning stiffness
c. other action
d. I never alter the dose and take regularly

25. Do you find it hard remembering to take your medication as prescribed? YES/NO

a. If NO: how do you remember to take (pain, meals)?

b. If YES: approximately how many doses would you forget per day?

26. Have you altered the dosage in any way
a. this week YES/NO
b. in the last 24 hours YES/NO
c. WHEN DID YOU TAKE THE LAST DOSE?

27. Do you find your current medication effective for:
a. casing pain?
YES/NO
b. reducing inflammation?
YES/NO
c. reducing morning stiffness?
YES/NO

d. anything else?

28. Do you have any problems or side effects with your present medication(s)?

YES/NO

(Does this affect your taking the medication?)
29. Have you ever taken any of the above medication previously? (NAME, DOSE, DURATION, WHY DID YOU STOP? WAS IT EFFECTIVE? HAS ANYTHING BEEN EFFECTIVE)?: TABLET BOARD

30. Have you ever had any of the following problems associated with any medication (now/previous) you have taken for $\overrightarrow{0}$ rheumatoid arthritis? (Ringing in ears/tinnitus, stomach upsets. nausea, vomiting, diarrhoea. headaches, confusion, skin rash $\vec{\omega}$ an allergy to, asthma, dizziness, weight gain or loss, sore mouth, a metallic taste. constipation).

Please indicate which medication

34. What do you expect your medication to do for your arthritis?

a. make it disappear or cure the arthritis

b. prevent it from getting any worse/progressing

c. to totally control the pain and stiffness

d. to temporarily reduce pain and/or stiffness?

35. a. Do you smoke, or have you ever smoked? How many years have you smoked?

How many cigarettes do/did you smoke per day?

b. Do you drink alcoholic beverages?

c. Do you drink large quantities of any liquid?

36. a. How old were you when you completed your schooling? 
b. Have you obtained any post school qualifications? (Circle the most appropriate)

(1) No

(2) Trade qualification

(3) Tertiary qualification

(4) Technical qualification

37. What is your major daily occupation? (Circle the most appropriate)
a. Full time student
b. Retired
c. Currently unemployed
d. Engaged in unpaid employment e.g. Home Duties
c. Engaged in paid/self employment

38. What is your major source of income? (Circle the most appropriate)
a. Aged/Widow's etc. pension
b. Superannuation
c. Invalid pension
d. War service pension
c. Wages
f. Self employment
g. Other

39. Do you own, are you purchasing, or do you pay rent for your home? (Circle the most appropriate)
a. Fully owned
b. Purchasing/paying off a mortgage
c. Pay rent
d. Occupy rent free
c. Other

How would you grade disability in this patient? (Circlc or tick most appropriatc).

1. Complete ability to carry out all usual dutics without handicaps. 2. Adcquate ability for normal activitics despitc handicap or discomfort or limited movement of one or more joints.

3. Ability limited to few or none of the dutics of usual occupation or self carc.

4. Incapacitated, largely or wholly; bedridden or confined to wheelchair; little or no self care.
DISABILITY SCORE — IMPACT

PATIENT WEIGHT

HEIGHT

ESR

CRP

BETA $_{2}$ MG

RF

ALBUMIN

CREATININE

DRUG

PLASMA LEVEL

\section{CURRENT LMO}

\section{COMMENTS}

\section{Joints Orrently Affected}

(Joints exanined by Doctor)

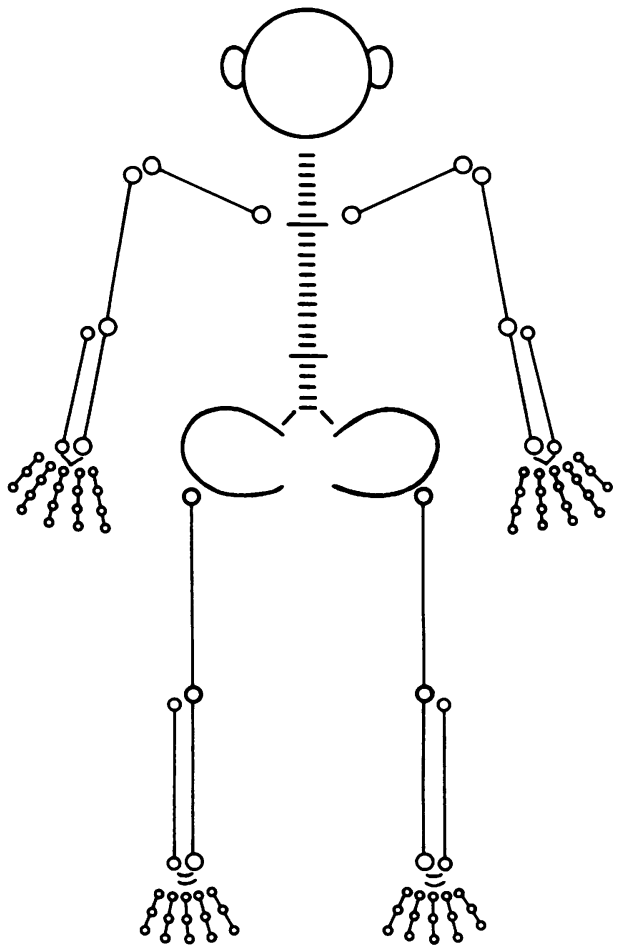

